Tone Svetelj

Boston College, Merrimack College and Holy Cross Hellenic College, Massachusetts, USA

\title{
Universal Humanism \\ - A Globalization Context is the Classroom of Unheard Options how to Become More Human
}

\begin{abstract}
Within the context of multi-cultural and multi-religious society, embedded in the process of globalization, a traditional understanding of humanism offers insufficient frameworks for an adequate comprehension of human flourishing and human search for meaning. In addition, modernity frames and evaluates in many aspects insufficiently the incomparable worth of the human person.

This article offers some guidelines for further philosophical, theological and pedagogical reflection on a humanism that is more suitable for our life in the process of globalization and modernity. Such humanism continually moves us toward a better comprehension of what "human" means within a universe of divergent cultures, religions, traditions, and races. This humanism is called universal humanism, based on the Greek word $\kappa \alpha \theta 0 \lambda$ ov, comprising both universality and wholeness. The first part of this article analyzes some of the main characteristics of humanism in the Greek and Roman contexts, which provide historical and theoretical frameworks for universal humanism. The second part justifies the relevance and usefulness of such humanism: it helps us to transcend singular cultures, nations, political systems, religions, and, by default, to discover or explore anew the meaning of the human person on a global level. The last part of this article suggests some pedagogical attitudes that will help us to embrace and remain in a dialogical relationship with all of humanity, in order to enrich our comprehension of the incomparable worth of the human person, this time from a universal perspective.
\end{abstract}

\section{Keywords}

Universal humanism, globalization, secularization, modernity, politics of recognition, human flourishing. 
From the very beginning of his papacy, John Paul II had focused on the renewal of modern culture from the very beginning of his papacy. He opposed not only the main ideologies of the late twentieth century (Marxism, Communism), but also ways of thinking that lead to degradation or disintegration of the human person. Modern consumerism, relativism, indifferentism are expressions of the thinking he opposed.

At the beginning of his Encyclical Evangelium Vitae, John Paul II discusses the incomparable worth of the human person. He also acknowledges that "new threats" have emerged, such as poverty, hunger, genocide, and euthanasia. He argues that these new threats diminish human dignity and life'. In his article John Paul II and the Crisis of Humanism², George Weigel describes John Paul II's opposing to what is threatening human dignity in terms of radical humanism, i.e. a culture of life-forming commitment to the inviolable mystery of the person. Such commitment includes manifold tasks: it recognizes what is human in every culture, fosters human freedom, regards a human body as something that is priceless, and respects human rights in every specific situation.

John Paul II's successor Pope Benedict XVI continued with the renewal of the universal Church in a different way but with a similar intention. With a special emphasis on the Western Societies, Benedict XVI focused on Jesus Christ, a figure who is primarily the revelation of the human condition and also the inspiration for our striving toward a new humanism. New humanism is diametrically opposed to secularist modern Western societies, which are based on relativism.

The present pope, Francis, continues John Paul II and Benedict XVI's direction with a special emphasis on the poor, suffering, marginalized, and youth, who are most vulnerable to social inequalities and social injustice. At the same time, Pope Francis emphasizes the importance of dialogue with all people, as well as the necessity of respect for the whole of creation. All these emphases aspects can too easily remain obsolete because they reveal to us the weaker aspects of a particular society and its lack of striving for a higher quality of human life.

Keeping in mind the incomparable worth of the human person and the need to face the obscure dimensions of modernity as the last three Popes

1 Evangelium Vitae, 2-3.

2 G. Weigel, John Paul II and the Crisis of Humanism, First Things, Dec. 1999, http://www. firstthings.com/article/2007/01/john-paul-ii-and-the-crisis-of-humanism-19 (03.12.2013). 
have presented them, I will offer guidelines for further philosophical and theological reflection on a humanism that is more suitable for our life in the process of globalization. Such humanism continually moves us toward a better comprehension of what "human" means within a universe of different cultures, religions, traditions, and races. I call this humanism universal humanism, based on the Greek word $\kappa \alpha \theta \mathrm{o} \lambda \mathrm{ov}$, comprising both universality and wholeness. In this article, I first analyze some of the main characteristics of humanism in the Greek and Roman contexts, which provide historical and theoretical frameworks for universal humanism. In the second part of the article, I justify the relevance and usefulness of such humanism: it helps us to transcend singular cultures, nations, political systems, religions, and, by default, to discover or explore anew the meaning of the human person on a global level. Finally, I suggest some pedagogical attitudes that will help us to embrace and remain in a dialogical relationship with all of humanity, in order to enrich our comprehension of the incomparable worth of the human person, this time from a universal perspective.

When referring to universal humanism, I will position the globalization process as a unique opportunity to rediscover what it means to be "human". At the same time, I am aware that my approach remains limited because "being human" can express him/herself only within temporary and spatial coordinates. Furthermore, my approach might be challenging for a serious theological reflection that starts from a transcendental reality and not from human nature. Even though universal humanism as presented in this paper seems like an abstract idea, it can enrich both our theological reflections as well as any reflection on what "being human" means on a more universal level.

\section{From Humanism to Universal Humanism}

The term humanism includes many different meanings. The common denominator of these definitions is man and his status, importance, powers, achievements, interests, or authority. Historisches Wörterbuch der Philosophie $e^{3}$ offers a general overview of various historical periods in which humanism finds different connotations. At their core, all humanists support

3 J. Ritter, R. Gründer (eds.), Humanismus - Historisches Wörterbuch der Philosophie, Basel / Stuttgart 1974 Schwab \& Co Verlag, Bd. 3, p. 1217. 
what is genuinely human and also strive for a noble human life and way to thinking. In other words, humanism includes everything that "helps us to cultivate higher human nature" . Tracing humanism back to its roots in ancient Greece and Rome also provides a deeper understanding of the term.

In Humanismus und Interkulturalität, Mohamed Turki summarizes three main characteristics of the original meaning of humanism in the Ancient Greek and Roman context ${ }^{5}$. The first characteristic of humanism is the belief that man exists at the center of the universe and is the measure of everything in the universe. In this sense, Protagoras claims that man is the measure of all things: of the things which are, that they are, and of the things which are not, that they are not. Following this claim, Protagoras queries the nature of truth as something absolute on the one side, and on the other side, relocates the position of man in the cosmos and in front of gods. Man should not be stretched anymore between the worlds of physis and metaphysis, which is in this case the world of gods, pulling him in two opposite directions; man should find anew his place in front of these two worlds. By introducing man as the measure of everything, Protagoras does not refer to subjectivism or individualism as some contemporary thinkers like to do; he rather introduces a new awareness of the essence of human, based on what human is.

The second characteristic of humanism in the ancient Greek context is the relevance of human reason and human ability of thinking. The pre-Socratics, especially Anaxagoras, introduce the cosmological concept of nous, mind, i.e. the principle of universal thinking and acting. The nous-principle plays an important rule in the creation, development, and organization of the worldorder. Later on, the Sophists and Socrates conceive this principle in terms of human lineaments, what becomes the measure for thinking and ethical acting of the individuals. After critical examination, the ethical values find their place in a philosophical system, reinforcing man's feeling of autonomy in front of the transcendental powers of gods. The Stoics elaborate on this idea of autonomy, especially when they talk about unity and equality of humans.

The ancient Greeks' third characteristic of humanism is the belief in the human progress and development of the human nature. For this reason, the Sophists underscore the importance of Paideia, education. A child's upbringing

4 Historisches Wörterbuch der Philosophie, p. 1217.

5 M. Turki, Humanismus und Interkulturalität, Ansätze zu einer Neubetrachtung des Menschen im Zeitalter der Globalisierung, Leipzig 2010, Edition Hamouda, p. 30-32. 
must include conscious development and continuous growth of the individual and community. For this reason, an individual or a community should separate $\mathrm{him} / \mathrm{her} /$ itself from the external transcendental powers and become the measure of everything. The nous-principle serves as the medium for recognition, domination, and transformation of their inside and outside nature.

The ancient Greeks' ideals of humanism take on slightly different features in the Roman context. According to A. Buck's writing on humanism ${ }^{6}$, the primary Roman meaning of humanitas relates to the Greek philantropia, i.e. love of man in the sense of caring for, nourishing, and enhancing the quality of life. Unlike the Greeks who were excluding foreigners and protecting their cultural assets, the Romans were including others into their new community. Love of mankind or humanity becomes a virtue, and distinguishes a virtuous person from a savage. Cicero deepens humanitas with a new spiritual dimension: humanitas is something that man acquires as a result of his education, which then challenges him to raise himself beyond human crudeness toward a higher level of existence. Man's humanness is based on his education and spiritual position, rather than his social status or background.

At this point, humanitas takes on two crucial functions: it becomes a social virtue that teaches us how to relate to other people; at the same time, it is an individual and educational ideal which provides us with standards for a higher existence through which we can realize a sense of self. Humanism embraces "moral and spiritual education, human magnanimity, dignity and respect, wit, gracefulness, sensitivity, inner evenness, mildness, kindness, and generosity" . Following this line, education becomes the differentiationprinciple not only between educated and non-educated people, or between knowing and not-knowing, but also between Romans and 'barbarians'. Barbarian in this case means much more than being not-Roman, such as in the case of the Greeks. Barbarian refers to those who do not enjoy the importance of a specific education and do not want to be aware of who/what we can become and what differentiates us from the others.

Understanding of humanism assumes new connotations and meanings in the time of Humanism, Renaissance, Enlightenment, and other periods of our Western history. How to understand humanness remains as one of the

6 A. Buck, Humanismus - Seine Europäische Entwicklung in Dokumenten und Darstellungen, München, Freiburg 1987, Karl Albert Verlag, p. 13.

7 Historisches Wörterbuch der Philosophie, p. 1231. 
crucial challenges of Modernity. Intentionally, I do not want to move beyond the Greek and Roman interpretations because their reflection provides us with sufficient information for universal humanism. In agreement with Protagoras, universal humanism retains man as the center and measure of everything, not in the sense of modern subjectivism and individualism, but as a new awareness of the essence of being human in the context of globalization. This humanism promulgates a new world order and ethical thinking, striving for unity and equality of humans on the global level. It also requires a new upbringing and mind-transformation, allowing us to accept the other in his/her humanness with his/her uniqueness, originality, diversity, dignity, strangeness, and mysteriousness. In one word, this humanism is universal in the sense of the Greek $\kappa \alpha \theta \mathrm{o} \lambda \mathrm{ov}$, comprising both universality (universal, general, altogether) as well as wholeness (entire, at all, whole, all inclusive). As such, it allows us to take into harmonious account present and deceased members of other nations, cultures, and religions. This effort will allow all of us to continue our search for further flourishing and peaceful coexistence in the context of globalization.

Next to its spatial and temporal universal dimension, this humanism also refers to the wholeness dimension, which incorporates all dimensions of human existence into a new whole, therefore integrating material, bodily, religious, spiritual, individual, social, and all other levels of human existence into a new unity. Such a wholeness dimension should not be taken for granted because there are certain forms of humanism in Modernity that seem to be exclusive in their reflection on humanness. These forms struggle to incorporate the lesser aspects of human existence into a meaningful account. I will further explore these aspects in the second chapter.

\section{Universal Humanism in the Context of Globalization}

Why should a worldview in terms of universal humanism be more suitable for our world of globalization than other similar accounts, and what are the advantages of such a worldview? These are the two main concerns of the second chapter. Charles Taylor's critique of the mainstream secularization theory provides a useful frame for these questions. His alternative interpretation of secularization in the context of Modernity rewards religion a constituent place and also combines other secularization theories into a new synthesis. His 
critique of the mainstream secularization theory also offers some essential elements for universal humanism ${ }^{8}$.

In A Secular Age, Taylor claims that religion occupies a different place in Modernity than in the $16^{\text {th }}$ century. Contemporary religious practices are changing and declining to a certain extent, and the modern human agent looks for less traditional ways of fulfillment. Unlike mainstream secularization theories, Taylor does not believe that religion is disappearing, losing its role, or that the human agents in Modernity are less spiritual or religious than in the past. Secularization as the retreat of religion from public space or the decline and alteration of religious practices is not a new idea in Modern thought. However, we ignore the heart of the process of secularization in Modernity if we stop with these wide-ranging terminology and concepts. For this reason, Taylor proposes a different theory of secularization, based on the idea that history has always experienced constant changes of religious forms and motivation. What is new in our time is that religion has to find and reestablish its place within the historical context of Modernity, providing us new and meaningful horizons?.

Taylor defines Modernity as "an unheard pluralism of outlooks, religious and non- and anti-religious, in which the number of possible positions seems to be increasing without end"10. Presently, we have completed the transition from a society in which belief in God was unchallenged and unproblematic to a society in which belief in God is once again understood to be one option among others, and frequently not the easiest one to embrace ${ }^{11}$. Taylor describes this transition in terms of the nova effect, i.e. "spawning an ever-widening variety of moral/spiritual options, across the span of the thinkable and perhaps even beyond" 12 . As a result, the believer, facing this steadily widening gamut of options, finds himself in a very intriguing choice-making process, which is in Modernity much more complex and challenging than it was in the past. Faith and religious life become one option among many others (e.g. unbelief,

8 C. Taylor, A Secular Age, Cambridge, Massachusetts, and London, England 2007, The Belknap Press of Harvard University Press.

9 A Secular Age, 423-437.

${ }^{10}$ A Secular Age, 437.

${ }^{11}$ A Secular Age, 3.

12 A Secular Age, 299. 
atheism, materialism, different forms of exclusive humanism), and for many people ultimately a nonviable one.

Taylor's theory of secularization also offers us a paradigm of how to broaden and justify our reflection about universal humanism. In our time of globalization, one has to face many alternative interpretations of what we consider to be human. These interpretations are often grounded on something that is more or less unknown to us, and brought to us from foreign cultures, religions and traditions. Such encounters might be weakening our traditional values and principles, essential for our understanding of humanism. Nonetheless, these encounters with what is unknown and foreign to us create at the same time "an ever-widening variety of moral/spiritual options", which are so numerous and extensive in our time of globalization that we can talk about a phenomenon without precedence in human history. As unsettling as it seems, this phenomenon provides us a new horizon of unexplored spiritual, religious, moral, emotional, cultural potentials for our reflection on what it means to be human, and what can help us to become more human.

Let us presuppose that we who are living in modern Western societies are in search of a meaningful and fulfilled life. Let us assume also that in the same way as we do, every nation, culture, religion, tradition, as well as subgroups within these cultures, traditions and religions, strive to an atmosphere in which their agents could reach their fulfillment, find something meaningful for their life, and consequently become more human. If this is the case, Taylor claims, then we "owe equal respect to all cultures..." because "all human cultures that have animated whole societies over some considerable stretch of time have something important to say to all human beings"13. When living in a society immersed in the process of globalization, we have an unprecedented opportunity to discover and explore the richness of human potential on the global level, which shall help us to deepen our understanding of humanness. Thus we are facing the nova effect not only in the sphere of religion as Taylor describes with his secularization theory, but the nova effect affects our life in a much broader level of our existence.

In other words, the humanism that includes all people and nations - for this reason I call it a universal humanism - allows us to discover in a new perspective what is universally human by transcending our spatial and temporal frames.

${ }^{13}$ C. Taylor, Multiculturalism, Politics of Recognition, New Jersey 1994, Princeton University Press, p. 6. 
Universal humanism permits us who live in modern Western societies to be at the deepest level of our existence in touch with commonalities among other human agents from the present and past times, both in and outside of Western societies. This humanism commits us to respect all specific definitions of humanism (Greek, Roman, German, Italian, Romantic, Christian, Muslim, Buddhist, exclusive, inclusive, and similar) on the one side, and on the other, challenges us to transcend them all and integrate each one of them into something what would be even more meaningful.

Each form of humanism can contribute abundantly to our reflection, but none of them should be taken as the self-sufficient or exclusive source. Universal humanism should become a narrative in which everyone can find his/her dwelling place, hold his/her identity, and at the same time welcome in a dialogical relation the Other, the unknown, and the foreign. Universal humanism creates a starting position that is not based on one specific culture, religion, nation, but on what all humans share in common, i.e. a search for meaning, happiness, flourishing, fulfillment, peace. As universal, it is not bound to one specific form of humanism or one specific religion, such as Islam or Christianity. Without any doubt, specific forms of humanism have played an extraordinary role in human history. Unfortunately, they are to a certain extent loaded with some negative emotions and experiences from our past, especially as related to questions of power and superiority of one culture over the others. For these reasons, they might be more hindering than helpful our research of what we have in common as humans.

In the first chapter, I mentioned that the Greek word $\kappa \alpha \theta 0 \lambda$ ov comprises a wholeness aspect of human nature as well. Intellectual honesty requires from us that our reflection on the human integrates all aspects of human existence: material, bodily, emotional, spiritual, religious, intellectual, individual, social, and all others; nothing should be excluded because everything is indispensable to humanness. The mysterious complexity of being human will come to light only if we are open to take into consideration all aspects of human existence. This is not something that advocates of humanism in Modernity take for granted.

In his reflection on Modernity, Charles Taylor addresses exclusive humanism, i.e. humanism which claims that fulfillment and fullness of human life can be reached exclusively within the domain of human power, making no reference to something higher that humans should reverence, love, or acknowledge ${ }^{14}$. This kind of humanism appears to be very attractive in

${ }^{14}$ Charles Taylor, A Secular Age, 19-21; 232-234. 
the secularized milieus because it allows us to go beyond the narratives of humanism that are based on religious principles. At the same time, it reinforces in the human agent the feeling of power to create a new order, based on benevolence and sense of freedom. Despite its powerful attractiveness, such exclusive humanism narrows human conditions and limits new possibilities for human flourishing and fulfillment. Based only on what can be found within humans, it closes the window to what transcends our human nature, i.e. religious and spiritual dimensions of human existence, as well as an immense gamut of possibilities for human flourishing, fulfillment and meaning.

As opposed to exclusive humanism, universal humanism integrates all dimensions of human existence, and in a particular way those dimensions which easily remain neglected because we struggle to include them in our account: violence, sacrifice, suffering, death, human body, ordinary human desires, sexuality, search for meaning in secular time, social inequalities, the poor and the marginalized, respect for nature, and all those dimensions which reveal limits, weaknesses, and fragility of human existence. Universal humanism refers us to the whole of human existence, respects every dimension of our life, and looks for such interpretation in which even the most fragile aspects of human existence find their meaning. The human agents living in modern Western societies can learn a lot from other cultures and religions, and consequently re-discover their own tradition and spiritual/religious/cultural heritage.

\section{Universal Humanism or How to Become More Human}

In this chapter, I offer two pedagogical and orientation guidelines that will help us on our way toward universal humanism; our willingness to be open to the other and necessity of a new terminology. These guidelines are based on humanitas as the Romans and philantropia as the Greeks understood them, i.e. love of man in the sense of caring for, nourishing, and enhancing the quality of human life, as well as believing in the continuous growth of individuals, regardless of whether or not they belong to our society. Such love and care taking is a virtue that will not happen by itself; it can be acquired through our self-transformation and education.

Having presented the frameworks of universal humanism only in outline and without necessary depth, one can conclude that we in Modernity are at the beginning of a future in which the human agent perceives himself breaking 
out from the past frames into a broader field, which challenges him to look for a new sense of religion, spirituality, culture, nationality, society, economy, politics, including the meaning of secularization, in an universal or global way in which everything is interwoven.

Interconnectedness and interdependency are not hypothetical statements; they are our reality. The crucial question at this point is not any more a hermeneutical problem of how to talk in Modernity about religious, spiritual, cultural, or other similar issues, but whether or not we really want to be open to the broader horizons of globalization. If we hesitate to answer this question, we need to answer the second question: are we aware of how much we are shutting out if we do not try to be open to the others? Taylor formulates a similar question in a different way: are we willing to recognize the equal value of different cultures, which means that we not only let them survive but acknowledge their worth $?^{15}$ Taylor continues that is primarily a moral question, requiring from us to take a position. "Our" recognition of "them" and our exposure to their position is not something that would happen automatically or where our passive observation from afar would be sufficient; our exposure requires from us an active participation in terms of reflection, making decisions, devotions, and practices, what will challenge to all of us to become more human ${ }^{16}$.

An affirmative answer to this dilemma does not necessarily mean that we are assured positive results and success. We cannot elaborate a strategy with clear goals of what we will achieve. This article does not propose a clear solution that will establish and perpetuate universal humanism. Nevertheless, what we can do is focus on our modes of being, studying, and living, using our experiences rather than modes from our history to come to know the others. Universal humanism as it is proposed in this article should not be taken as a normative plan, based on clearly defined ideals; it is rather a descriptive

${ }^{15}$ C. Taylor, Ethics of Authenticity, 64.

${ }^{16}$ As a possible example of what to do, I refer to Kwame Anthony Appiah's book Cosmopolitanism, Ethics in a World of Strangers, in which the author argues that in twenty years, at a cost of about $\$ 150$ billion a year, the richest nations can eradicate extreme poverty - the poverty that kills people and empties lives of meaning. The richest nation can together salvage lives of the poorest human beings, by spending collectively less that a third of what the United States spends each year on defense all by itself. This is not an impossible demand, nor a monstrous or unreasonable obligation, nor heroism, but the matter of our clearheadedness. It is a demand of simple morality, or a response to what Adam Smith called "reason, principle, conscience, the inhabitant of the breast". Kwame Anthony Appiah, Cosmopolitanism, Ethics in a World of Strangers, W. W. Norton \& Company, New York, London, 2006, p. 173-174. 
path, challenging and inviting us to look courageously for what universal human means. Our answers will most likely be different depending on the specific context.

Despite all of this imprecision, universal humanism should not be taken as a utopian notion of a good about which we know that we will never reach. Universal humanism is rather an encouragement to search for what we have in common as humans, what shall reinforce and enrich our further discussion and peaceful coexistence based on hope that all of us will be well. The same "hope" is already something what we all share in common, even though we express it in different ways. For example, Christians and Muslims discuss what will happen in Heaven, Jews believe that the best is yet to be, Buddhists believe in Nirvana or a great release from life conceived as a burden, and the Confucianists emphasize the importance of the Way.

When searching for the answer to what we have in common as humans, it is important to be aware of proposing our strong convictions as universal solutions. For example, some people believe that "our" understanding of democracy can be imposed on other countries; that religious principles should be generally separated and isolated from politics, economy, social life; or that the highest achievements in art, literature, music belong exclusively to the cultures of the first world and represent the non-discussed criteria for evaluation of other cultures. Following this line, one could list similar positions based on Europe- or America-centrism, the world economy and mass media as the form of modern colonialism, and other similar cases, in which those in power too easily impose their solutions, ways of thinking, and lifestyle onto those who have less power ${ }^{17}$. This might be functioning in the past; for sure it will not be appropriate for our present and future coexistence in the context of globalization. Facing our past may be a very humiliating experience, which might at the same time become an extremely rewarding and enriching experience for our present.

Instead of proposing or even imposing "our" solutions, universal humanism challenges us to look first for what we already have in common. For example,

${ }^{17}$ A scholarly example of necessity and manifolds benefits of being more open and less prejudicial is a discussion provoked by Edward Said's book Orientalism. This highly influential and controversial book, published in 1978, changed in many ways understanding of what we Westerns believe to be Orient, based on one-sided assumptions underlying Western attitudes toward the Middle East. Even recent military invasion of Iraq can be taken as an expression of subtle Western bias against Arab-Islamic cultures. 
from Amartya Sen's article Democracy and Its Global Roots ${ }^{18}$, we can learn that democracy as we know it in the West, especially in the United States, does not exclusively originate in the ancient Greek civilization. Ancient cultures in the territory of the present India, China, Japan, Korea, Iran, Turkey, the Arab world, and many parts of Africa were familiar with a long tradition of encouraging and protecting public debates on political, social, and cultural matters. In addition, Amartya Sen notices, "there is a great reluctance to take note of the Greek intellectual links with ancient Egyptians, Iranians, and Indians, despite the greater interest that the ancient Greeks themselves showed... in talking to them"19. From this example we can learn that "our Western" understanding of democracy can be easily enriched and enlarged with other non-Western interpretations. Before we propose or impose a solution to "them", universal humanism reminds us that we should rather look for what we have in common, and listen to what "they" would propose as an acceptable solution, based on their historical/cultural/religious backgrounds.

Another useful pedagogical guideline for the creation of universal humanism is the matter of terminology. When Charles Taylor talks about the human agent's search for meaning and fullness of life, he does not use religious terminology. Such a language would remain in our time heavily loaded with emotions and historical experiences that aggravate our comprehension, especially of those who do not share with us the same religious convictions. Taylor rather imposes his narrative in terms of human flourishing, fullness and richness of life, search for meaning, and freedom, which are universally human. People of all times are looking for ways to make life fuller, richer, deeper, more worthy, and more admirable. Such terminology has an attractive and transformative power, grasping attention of the modern agent, and simultaneously unsettling his sense of the ordinary being in the world. In his search for fullness, richness, meaning, and freedom, the human agent faces the crucial question whether in his search he recognizes something that might challenge his limited understanding and open his mind to new areas where he might find a satisfactory answer.

I find Taylor's terminology also suitable to our search for universal humanism. Every individual and society, culture, religion, and nation looks for what will bring something meaningful into our life. Human flourishing,

${ }_{18}$ Amartya Sen, Democracy and Its Global Roots, Oct. 6, 2003, The New Republic, p. 28-35.

19 Ibid, p. 30. 
fullness and richness of life, freedom, can be assumed as a universal shared terminology, referring us to what is universally human, and what makes us makes who we are. It is true that our comprehension of these terms might vary according to our historical, cultural, religious context; nonetheless, these terms allow us to construct some bounds with others before we start talking about specific matters.

Universal humanism as presented in this article might appear stronger in its opening and provoking new questions than rather providing satisfactory answers. In whatever position we take on Modernity and globalization, it is better that our position is more inclusive than exclusive; it is always more rewarding to focus on what makes our life more human and allows us to become what we are supposed to become. In this sense, the present Pope courageously indicates at the exigent dimensions of Modernity and globalization. The globalization context presents itself as a classroom of unheard new possibilities. A sane curiosity and intellectual humility, simplicity of life, and willingness to open ourselves might be a good starting point.

\section{Bibliography}

Appiah K.A., Cosmopolitanism, Ethics in a World of Strangers, New York, London 2006, W. W. Norton \& Company.

Buck A., Humanismus - Seine Europäische Entwicklung in Dokumenten und Darstellungen, München, Freiburg 1987, Karl Albert Verlag.

Ritter J., Gründer R. (eds.), Humanismus, Historisches Wörterbuch der Philosophie, Basel / Stuttgart 1974, Schwab\&Co. Verlag.

Sen A., Democracy and Its Global Roots, Oct. 2003, The New Republic.

Taylor C., A Secular Age. Cambridge, Massachusetts, and London, England 2007, The Belknap Press of Harvard University Press.

Taylor C., Multiculturalism, ed. Amy Gutmann, New Jersey 1994, Princeton University Press.

Turki M., Humanismus und Interkulturalität, Ansätze zu einer Neubetrachtung des Menschen im Zeitalter der Globalisierung, Leipzig 2010, Edition Hamouda.

Weigel G., John Paul II and the Crisis of Humanism, Dec. 1999, First Things. 